\title{
LA INDUSTRIA ESPAÑOLA DEL CINE Y EL IMPACTO DE LA OBLIGATORIEDAD DEL DOBLAJE EN 1941
}

\author{
por \\ JOSEP ESTIVILL PEREZ \\ Cercle $d^{\prime}$ Estudis Histórics i Socials «Guillem Oliver». Tarragona
}

RESUMEN: En 1941 la administración franquista obligó a doblar al español todas las peliculas babladas en lengua extranjera. Fue una decisión polémica y vista como negativa por los directores, productores, guionistas, etc. Los bistoriadores opinan que el doblaje abrió una terrible crisis en la industria cinematográfica española. Piensan que las autoridades tenian prejuicios xenófobos contra las lenguas extranjeras, pero un análisis profundo revela otras posibilidades como, por ejemplo, el proteccionismo económico.

PALABRAS CLAVE; Historia de España. Edad Contemporänea. Franquismo. Cultura. Industria. Historia del cine.

ABSTRACT: In 1941 the Francoist administration ordered all foreing-language films to be dubbed in Spanish. This was a controversial decision and was seens as a negative one by directors, producers, screenwriters, etc. Historians say that dubbing created a terrible crisis in the film industry in Spain. They think that the authorities bad xenophobic prejudices about foreign languages, but a deep analysis reveals other possibilities such as, for example, economic protectionism.

KEY wORDS: Spanish History. Modern history. Fracoist regime. Culture. Film industry. Film history.

\section{INTRODUCCION 1}

En 1941 tuvo lugar un hecho de la máxima importancia para la industria del cine nacional cuando la administración franquista obligó a doblat al español todas las películas habladas en lengua extranjera. Esta medida sería considerada como uno de los factores desencadenantes de la crisis del cine español y, desde

1 El autor recibió en 1995 el beneficio de un beca del programa de estudios «Joan Maragail» concedida por la (Fundación José Ortega y Gasseb) de Madrid y la Fundació «La Caixa» de Barcelona.

Higpania, LIX/2, núm. 202 (1999) 677-691 
entonces, la mayor parte de historiadores y analistas no han hecho sino ratificar su trascendencia y gravedad. Fernando Méndez Leite ya se declaraba ese mismo año de 1941 enemigo convencido del doblaje al que juzga perjudicial para el cine nacional ${ }^{2}$, y Juan Antonio Cabero en 1949 lo considera un error de bulto culpable de la larga y penosa miseria de las películas españolas ${ }^{3}$. Las mismas opiniones se han repetido de manera unánime hasta llegar a las obras más recientes y especializadas como la monografia de Santiago Pozo sobre la historia de la industria cinematográfica española publicada en 1984.

Menos unanimidad, por el contrario, ha habido para razonar las causas de su imposición. Las explicaciones ofrecidas son en general de tipo ideológico o político y aluden al nacionalismo lingǘstico del régimen, un concepto que hizo fortuna en los años 70 de la mano de Román Gubern ${ }^{5}$, y que posteriormente han recogido la mayor parte de los historiadores con muy pocas excepciones. Una de éstas la aporta José Enrique Monterde al sugerir que el recubrimiento ideológico escondía en realidad un regalo para favorecer los intereses económicos de algunos sectores monopolísticos adictos al régimen ${ }^{6}$. Pero desgraciadamente los autores han mostrado, en general, un escaso interés por atender las fuentes coetáneas, lo que nos lleva a sugetir que estas explicaciones han sido quizás poco afortunadas, o al menos, insuficientes. Nuestra investigación pretende superar las limitaciones derivadas de la mera repetición de tópicos forjados sin pruebas documentales solventes. De esta forma, el presente artículo se adhiere al espiritu revisionista de Alberto Elena en «Quién prohibió "Rojo y Negro"?"), una verificación de los rumores sobre la supuesta prohibición por altas jerarquías en 1942 de la película de Carlos Arévalo titulada «Rojo y Negro» debido al tratamiento inadecuado de la temática falangista. Ninguna prueba se aportaba al respecto salvo la mutua cita de los historiadores entre sí, pero ello no impedía que se diera como válida lo que no era más que una simple hipótesis sin demostrar, tan válida como cualquier otra; por ejemplo, la que atribuye la aparente desaparición del film a las estrategias comerciales de la productora ?

$\mathrm{El}$ análisis sin prejuicios de la imposición del doblaje en 1941 permite identificar algunas claves económicas, suplementarias a las ideológicas - prácticamente las únicas hasta el momento aceptadas-, las cuales nos aportan nuevos elementos de juicio para entender una de las disposiciones legislativas más im-

2 MÉNDEZ-LEITE, F.: Cuarentay cinco años de cinema español, Madrid 1941, pág. 203.

3 Cabero, J. A.: Historia de la Cinematografia Española, Madrid 1949, pág. 662.

4 Pozo ARenas, S: La industria del cine en España. Legislación y Aspectos Económicos (18961970), Barcelona 1984, pág. 51.

5 GUBERN, R. y FONT, D.: Un cine para el cadalso. 40 años de censura cinematográfica en España. Barcelona 1975, págs. 34-37.

" MONTERDE, J. E.: «El cine de la autarquía (1939-1950)», en AA.VV.: Historia del cine español, Madrid 1995, pág. 193.

7 EIENA, A.: «Quién prohibió «Rojo y Negro»?»: Secuencias. Revista de Historia del Cine, 7 (octubre 1997), págs. 61-78.

Hispania, LIX/2, núm. 202 (1999) 677-691 
portantes para la cultura española durante el franquismo puesto que, además de los efectos económicos, el doblaje obligatorio permitiría a la censura alterar los diálogos de las películas para manipular con ello el contenido de una de las fuentes de información más influyentes sobre la opinión pública.

Peto la imposición del doblaje, sin embargo, no tenía como objetivo primordial manipular los diálogos de las películas ni perseguir las lenguas extranjeras sino que era consecuencia de la política económica de posguerra, una política ferozmente proteccionista. Hay que tener en cuenta que en 1939 la situación de la industria cinematográfica tras la guerra civil puede considerarse deficiente: los estudios de rodaje y laboratorios han quedado obsoletos, necesitados urgentemente de material de repuesto que sin embargo no puede fabricarse en el país; las productoras han paralizado su actividad; las distribuidoras han dejado de importar; y por encima de todo, el trauma psicológico de la guerra: asesinatos, exilio, etc.

\section{LA POLITICA ECONOMICA}

En este contexto los primeros esfuerzos de las nuevas autoridades se centran en la reconstrucción de la industria cinematográfica con el objetivo de incrementar la productividad para reducir la importación de películas extranjeras y evitar la constante salida de divisas, verdadera sangria para la maltrecha balanza de pagos.

La cuestión de las divisas llegó a convertirse poco menos que en obsesiva durante estos primeros años. Antonio de Obregón, secretario general del Departamento Nacional de Cinematografía, reconocía que «era tal la penuria de medios de pago al extranjero, que aun se pensaba obtener divisas, pocas o muchas, de la Cinematografías ${ }^{8}$. Se pretendía, además, que las enormes recaudaciones generadas por las películas extranjeras, importadas hasta el momento sin ningún tipo de restricción, redundasen --en parte, al menos-en beneficio del cine español. Con este objetivo el Ministerio de Industria y Comercio creó en octubre de 1939 la Subcomisión Reguladora de la Cinematografia, el organismo encargado de regular los aspectos económicos con la misión declarada de "poner las onerosas importaciones de «films» extranjeros al servicio de la industria nacionabs ?.

Con este mismo propósito el Ministerio de Industria y Comercio acababa de establecer a mediados de 1939 un decreto que obligó a realizar una película española por cada 10 películas importadas ${ }^{10}$. Este ordenamiento «no tenía carácter rígido en ninguno de sus aspectos ni se le dio tampoco oficialidad

8 Indice cinematográfico de España 1941, Madrid 1942, pág. 473.

- Orden de 20 de octubre de 1939 creando la Subcomisión Reguladora de la Cinematografia. Boletín Oficial del Estado, (BOE), 21-10-1939.

10 Texto recogido en la circular $n^{\circ} 105$ del Servicio Sindical - Cámara Española de Cinematografia. Arcbivo General de la Administración (AGA), Alcalá de Henares, sección cultura, c/270.

Hispania, LIX/2, núm. 202 (1999) 677-691 
desde el «Boletín Oficial del Estado», pues se quería antes ver y comprobar los resultados en la práctica ${ }^{11 . » Y} \mathrm{Y}$ los resultados fueron decepcionantes ya que las grandes empresas productoras norteamericanas - salvo Radio Films y Columbia - dispensaron una escasa acogida a la nueva modalidad de intercambio comercial ${ }^{12}$.

Sin embargo, lo interesante de la normativa citada es que la medida de fomento de la producción filmográfica incluyó en uno de sus artículos una disposición, escasamente conocida, que obligó a doblar al español y en estudios nacionales el $90 \%$ de las películas importadas ${ }^{13}$. Aún desconociendo el éxito real que hubiera podido tener la medida parece lógico pensar que las grandes distribuidoras del cine extranjero optaran progresivamente por doblar sus películas abandonando el antiguo sistema de exhibirlas en versión original con subtítulos. Teniendo en cuenta los altos índices de analfabetismo que todavía asolan al país, el doblaje era un sistema que permitía llegar a un mayor número de espectadores, y por tanto, tenía que ser más rentable. Por ello, parece lógico pensar que la progresiva substitución del subtitulado por el doblaje para hacer más accesibles las películas al gran público habría sido estimulada por las propias empresas distribuidoras y exhibidoras. Este hecho debe confrontarse con el tópico repetidamente expuesto que atribuye la iniciativa del doblaje a la ideología nacionalista y xenófoba del régimen franquista - Santiago Pozo incluso sugiere que fue idea del mismo general Franco- ${ }^{14} \mathrm{y}$ debe recordarse que, de hecho, ya en tiempos de la República, en 1935, una comisión de representantes del sector de la distribución y la exhibición se entrevistaron con el ministro de hacienda, Joaquín Chapaprieta, para solicitar un trato de favor hacia el doblaje de las películas extranjeras, considerando ésta la única manera para rentabilizar su importación ${ }^{15}$.

La progresiva implantación del doblaje durante el periodo republicano queda atestiguada por diversos autores. Luis Miguel Quiroga Valcarce ha comentado, para la región gallega, que ya en 1932 este procedimiento se había impuesto como sistema habitual para la presentación de films extranjeros ${ }^{16}$. Y Román Gubérn que la empresa Metro-Goldwyn-Mayer, una de las más fuertes en el sector de la distribución, impulsó el doblaje desde sus estudios en Barcelona para que sus películas fueran mejor recibidas por los espectadores ya que el subtitulado tenía el inconveniente de su incomprensión para la población analfabeta que ni tan siquiera contaba con el paliativo de la traducción en voz alta como ocurría en la época muda ${ }^{17}$. Una práctica, la del «doblaje espontá-

\footnotetext{
11 Indice..., págs. 472-3.

12 Garcí, P.: «La exportación de películas españolass: Primer Plano, 3 (3-11-1940), pág. 24.

13 Circular $n^{\circ}$ 105. Doc. cit.

14 Pozo Arenas, S.: La industria..., pág. 51.

15 FANÉ, F.: El cas Cifesa: vint anys de cinema espanyol (1932-1951), Valencia 1989, págs. 147-148.

16 Quiroga VALCARCE, L. M.: «La implantación del cine sonoro en Galicia», en E/ paso del mudo al sonoro en el cine español. Actas del IV Congreso de la Asociación Española de Historiadores del Cine (AEHC). Madrid 1993, pág. 96.
}

Hipania, LIX/2, núm. 202 (1999) 677-691 
neo", cuya existencia recuerda el crítico de cine Joan Francesc de Lasa de su infancia en los cines de barrio poco antes de la aparición del cine sonoro ${ }^{18}$. Finalmente, las revistas de la época recogen la protesta de algunos intelectuales como el prestigioso crítico Sebastià Gasch que lamentaba en la revista «Miradons el hecho de que sólo unas pocas distribuidoras se mantenían fieles al sistema del subtitulado ${ }^{19}$.

De esta manera, podemos ver como en la etapa anterior al franquismo muchas empresas del sector acuciadas por las leyes del mercado apostaron por el doblaje. Pero además, poco después de la guerra, y según el autorizado testimonio de Victoriano López García - experto en aspectos técnicos e industriales en la Subcomisión Reguladora de la Cinematografia-, fueron las tres grandes empresas de la industria española del cine - Cifesa, CEA y Ulargui Films-las que solicitaron la obligatoriedad del doblaje ${ }^{20}$. Una de las solicitudes se halla en el informe -inédito - elaborado por CEA sobre el estado en el que se encuentra el sector cinematográfico tras la guerra civil y que fue enviado a las autoridades en enero de $1940^{21}$ :

«Atraviesa esta rama de la Economía Nacional, la misma crisis, que atravesó en los desastrosos tiempos pasados.

Se trata de una industria que nació bajo los más nobles y favorables augurios, con la Einalidad exclusiva de redimir a los españoles de la contínua salida de capital en pago de películas extranjeras y poner a nuestra Patria en condiciones de exportar nuestra propia producción con la natural secuela de exportat también cultura, arte, trabajo, propaganda, etc. etc.

Nada se ha conseguido hasta la fecha en favor de la Cinematografía Nacional, ni aún siquiera siguiendo nuestro mal o buen espiritu de adaptación o de copia, continuándose importando numerosos títulos extranjeros cada año, sin otro gravámen que el aduaneto ascendente a unas mil pesetas por título, dando por sentado que todos los importados satisfagan los referidos derechos. [...]

La Cinematografia Nacional precisa según nuestra opinión:

$1^{\circ}$. - Política de unidad.

$2^{\circ}$--Dependencia de un solo Ministerio [...].

$3^{\circ}$.- Limitación de la importación de películas extranjeras a un número máximo de Doscientas o Doscientas veinticinco por año, sin perjuicio de irla disminuyendo, teniendo en cuenta para el contingente de cada Nación las normas que se indiquen. $4^{\circ}$-Obligación de doblar o sincronizar al español en estudios españoles y por artistas y obreros españoles el ochenta por ciento de las producciones extranjeras que se importen

$5^{\circ}$.-Obligación para los importadores extranjeros de dejar el valor de la explo-

17 GUBERN, R.: «Voces que mienten», prólogo al libro ÁvLA, A.: La censura del doblaje cinematográfico en España. Barcelona 1997, pág. 11.

18 Juliachs, I. y Losilla, C. (coord.): La memòria crítica, Barcelona 1997, pág. 25.

19 GASCH, S.: «La persistència d'un abús. Ens donen gat per llebre», Mirador, 320 (4-41935), pág. 4.

20 FANés, F: El cas Cijesa..., pág. 147.

$21 A G A$, cultura, $\mathrm{c} / 723$. 
tación de sus peliculas en nuestra Nación con obligación de destinar todo o parte a la producción de una película española por el número de películas extranjeras que importen y que se acuerde.

$6^{\circ}$. - Ordenar como en los demás paises la obligatoriedad de exhibición en los cines de un número de películas españolas por el porcentaje que se acuerde de extranjeras.

$7^{\circ}$.-Facilidad para la exportación de nuestras producciones. [...]»

Este informe ya empezaba constatando la existencia de una crisis en el cine español y sugería, para superarla, la adopción de una serie de medidas claramente proteccionistas hacia la industria nacional y restrictivas hacia el cine extranjero. Poco menos que todas las sugerencias -incluida la obligatoriedad del doblaje- serian puestas en práctica unos meses después.

$\mathrm{La}$ insistencia de las productoras llevaría a los grandes organismos rectores de la industria y el comercio cinematográficos a estudiar a lo largo de 1940 la conveniencia o no de imponer obligatoriamente el doblaje. El Sindicato Nacional del Espectáculo se mostraba partidario para satisfacer con ello un triple objetivo: velar por la pureza del idioma, satisfacer las necesidades de los espectadores y proporcionar trabajo a numerosos trabajadores ${ }^{22}$. Sin embargo, el Departamento Nacional de Cinematografía temía la pérdida de competitividad que podía suponer para las películas españolas otorgar a las extranjeras el "arma del idioma», además de otros inconvenientes de índole técnica y arústica que no especificaba ${ }^{23}$. Los intentos por llegar a un entendimiento entre ambos organismos fracasarían y las posturas se mantendrían inamovibles durante ese año.

\section{LA IMPLANTACIÓN OBLIGATORIA DEL DOBLAJE}

Finalmente, sin embargo, las diversas medidas parciales culminaron en una disposición del Sindicato Nacional del Espectáculo del 23 abril de 1941 que - Sorprendentemente y a pesar de su importancia y carácter oficial- tampoco fue esta vez publicada en el Boletín Oficial del Estado. Se trataba de un paquete de medidas de protección a la industria cinematográfica para el fomento de la producción de films que establecía, en esencia, un gravamen a cada película extranjera importada. La cuantía de este impuesto variaba de acuerdo con la estimación de su previsible rendimiento comercial que realizaba una "Junta clasificadoran, y siempre debía ser de 75.000 pesetas para las películas consideradas como de uprimera categoria», 50.000 para las de segunda o 25.000 para las de tercera.

22 Oficio del Jefe del Sindicato Nacional del Espectáculo al Jefe del Departamento Nacional de Cinematografia, 8-7-1940. AGA, cultura, c/153.

23 Oficio del jefe del Departamento Nacional de Cinematografia al Jefe del Sindicato nacional del Espectáculo, 11-7-1940. AGA, cultura, c/153.

Hispanis, LIX/2, núm. 202 (1999) 677-691 
De las catorce normas de esta nueva disposición había dos que se referian concretamente a la cuestión del doblaje:

"Octava. Queda probibida la proyección cinematográfica en otro idioma que no sea el español, salvo autorización especial, que concederá el Sindicato Nacional del Espectáculo, de acherdo con el ministerio de Industria y Comercio y siempre que las peliculas en cuestión bayan sido previamente dobladas. El doblaje deberá efectuarse en estudios españoles que radiquen en territorio nacional y por personal español.

Novena. Además del canon establecido en los artículos anteriores, las películas de largo metraje, tanto de primera como de segunda y tercera categoria, pagarán en concepto de licencia de doblaje la cantidad de 20.000 pesetas cada una." 24 .

Esta nueva normativa sobre importación de films fue recibida, en general, con buenas dosis de optimismo por lo que comportaba de implantación de un sistema proteccionista. Asi se manifestó el Departamento Nacional de Cinematografía a través de algunos editoriales en la revista «Primer Plano», su virtual boletín oficial:

"Celebremos esta orden gue viene a poner término a un «estado inestable» en el sistema de las importaciones cinematográficas, por medio de una disposición dingida, con recto principio, a servir de apoyo a la productión española.» ${ }^{25}$.

Sin embargo, el Departamento, señaló dudas concretas por la cuestión del doblaje, del que reconoce que ya se venía practicando pero cuya imposición supondría la entrega de la mejor arma con que cuenta la producción española el lenguaje- a la producción extranjera ${ }^{26}$. En respuesta a estas inquietudes, el jefe del grupo de Cinematografia del Sindicato Nacional del Espectáculo, Antonio Pacheco, minimizó los efectos negativos:

"Hay quienes dicen que las peliculas dobladas al español perjudican nuestra producción, porque a su calidady tecnicismo le agregamos nuestro propio idioma. Pero estos inconvenientes los bemos subsanado con nuestra disposición, porque es evidente que la inmensa mayoría de las peliculas se vienen doblando: sólo un reducido porcentaje no incluyen esta comodidad para el espectador. Pues bien, bemos creido más beneficioso obligar a este reducido grupo a que las doblen y exigir que todas paguen las 20.000 pesetas por licencia de doblaje. Además, beneficiamos a la industria nacional, porque obligamos a que estos trabajos se bagan en territorio españoly por Empresas españolas.» ${ }^{27}$.

El Sindicato insistió al cabo de unos meses en la obligatoriedad de doblar todas las películas al español amenazando con imponer sanciones a los infrac-

24 La orden no está fechada pero algunos periódicos, como el $Y a$, la publicaron el día 24 de abril.

25 «Algunas consideraciones al nuevo régimen de importación de películas»: Primer Plano, 28 (27-4-1941), pág. 3 .

26 Ibidem.

27 «El camarada Pacheco explica algunas modalidades de ja nueva importación de peliculass: Primer Plano, 29 (4-5-1941).

Hipania, LIX/2, núm. 202 (1999) 677-691 
tores ${ }^{28}$. Esta insistencia indica que muy probablemente algunas distribuidoras, seguramente las más modestas, se mostraban reacias a la aplicación del doblaje; ello podría deberse no tanto a razones artísticas o ideológicas sino económicas puesto que se las obligaba a realizar una inversión suplementaria en unas películas viejas o de baja comercialidad cuya distribución prometía un escaso margen de beneficios.

De todas maneras, las primeras valoraciones oficiales hechas públicas, pasado un tiempo prudencial, fueron positivas. A finales de año, Tomás Borrás, jefe del Sindicato Nacional del Espectáculo, destacaba como principal beneficio la disminución de films importados con la consiguiente reducción de la salida de divisas, y la creación, con el dinero recaudado, de un fondo económico de varios millones de pesetas para el apoyo al cine español ${ }^{29}$. Este fondo permitió la concesión de créditos a las empresas con algún proyecto para la realización de películas, la convocatoria de concursos de guiones, la entrega de premios a las mejores películas españolas de la temporada, y finalmente, la concesión de 10 becas para el perfeccionamiento de la técnica cinematográfica ${ }^{30}$. También a finales de 1941 se estipuló una cuota de importación que autorizaba a importar títulos extranjeros solamente a los productores de películas españolas ${ }^{31}$.

Es importante recordar que todas estas medidas proteccionistas no eran exclusivas de las autoridades franquistas sino que, como explica Thomas H. Guback en sus libros sobre la historia de la industria cinematográfica internacional, se habian estado aplicando durante años en algunos países europeos como una defensa contra la creciente hegemonía de las empresas norteamericanas. Por ejemplo, la llamada cuota de importación fue implantada en Alemania en 1925 para obligar a financiar una película alemana por cada película extranjera importada, un ejemplo que pronto seguirian Francia, el Reino Unido e Italia. Además, estos dos últimos países aplicaton también las cuotas de pantalla para limitar la exhibición de películas extranjeras a unos determinados porcentajes en relación a las producciones nacionales ${ }^{32}$.

Con las medidas proteccionistas, y de manera similar a lo que sucedía en otros países de la Europa occidental, los impuestos a la importación y al doblaje de películas extranjeras permitieron la constitución de un fondo ecónomico que facilitó la realización de largometrajes, cuyo número aumentó consecuentemente durante los años siguientes. En 1940 se producen 24 películas largas y 31 en 1941 , pero en 1942 ya se consiguen 52 y en 1943 son 47 . No obstante, en

28 Circular del Jefe del Grupo de Cinematografia, 23-9-41, recogida por BErnABÉ, V, de: España cinematográfica. Anuario 1943. Madrid 1943, pág. 368.

29 Declaraciones al periodista Fernán en Primer Plano, 58 (23-11-1941), pág. 17.

30 "Orden de 11 de noviembre de 1941 por la que se dictan normas para dar aplicación adecuada a los fondos reunidos por el Sindicato Nacional del Espectáculo para protección y estimulo de la producción cinematográfica nacionab, $B O E$, 17-11-1941.

31 Orden del 28 de octubre de 1941. Ver Pozo, S.: La industria..., pág. 44 y ss. 21.

32 Recogido por BALlester, A.: La politica del doblaje en España, Valencia 1995, págs.19. 
1944 desciende hasta 34 y a 32 el año $1945^{33}$. No es fácil determinar las causas exactas que determinan las oscilaciones ni en qué medida pueden estar relacionadas con la legislación proteccionista de las autoridades. Además, no existe hasta el momento un catálogo frable de la producción durante aquellos años y las diversas estadísticas que se publicaron en su momento presentan notables diferencias entre sí, aunque sí parece demostrado que el sistema proteccionista permitió financiar buena parte de las producciones tealizadas por las productoras. Esto comportó, sin embargo, algunos efectos negativos, como por ejemplo, el auge del clientelismo, como nos explica nuevamente Victoriano López García:

«Los productores bacian peliculas para la Junta, para que les diera permisos, vendian los permisos que estaban sobre el millón de pesetas en el mercado libre y la pelicula [española] la colocaban en un estante. Si daba dinero o no, no importaba; ellos iban a buscar el permiso de importación. ${ }^{34}$.

En efecto, algunas de las películas españolas realizadas apenas se exhibían $y$, en ocasiones, ni tan siquiera llegaban a estrenarse. Una pequeña nota crítica en la revista «Primer Plano» aludía a este hecho:

«Secuestro de películas españolas.

Hay titulos de peliculas que sonaron en nuestros oidos en el momento de su rodaje, y sobre los cuales cayó luego el olvido y el silencio, pues pasó el tiempo sin que su estreno diera al público la oportunidad de conocerlas y a la critica de juzgarlas. [...] ¿Qué explica el secuestro? ¿Combinaciones mercantiles de distribuidores o exbibidores? 2 Quien me compra este misterio...? ${ }^{35}$.

\section{LA MANIPULACION DE IAS PELICULAS}

Además del riesgo de fomentar el servilismo entre los empresarios que podían sentirse tentados de realizar las películas pensando en satisfacer los gustos de la administración para obtener las compensaciones económicas, la imposición del doblaje reveló nuevas aplicaciones; por ejemplo, permitió a los organismos de censura alterar con mayor comodidad los diálogos y situaciones de las películas. Es ya conocida la manipulación que sufrió "Casablanca» (Michael Curtiz, 1942) el melodrama propagandista de la Warner que criticaba la colaboración del régimen de Vichy con los nazis, en cuya versión española se suprimieron las referencias del protagonista a su participación en las Brigadas Internacionales durante la Guerra Civil substituidas por una inofensiva alusión al Anschluss - la anexión de Austria al Tercer Reich en 1938-. Menos conocido es el caso de infinidad de películas que pudieron ser manipuladas de las que muy poco sabemos; una de ellas, es la alemana «La ciudad de oro» (1942), de la cual se ofrecen seguidamente, a modo de ilustración, algunos diálogos de

33 Culvas PUENTE, A. (dir.): Antario cinematográfico bispanoamericano, Madrid 1950, pág. 60.

34 Entrevista en Pozo, S.: La industria..., pág. 52.

35 Primer Plano, 73 (8-3-1942), pág. 12. 
la versión original —a la izquierda - y alterados en la versión doblada —a la derecha- en la que se incluyeron referencias religiosas ${ }^{36}$ :

\begin{tabular}{|c|c|}
\hline \multicolumn{2}{|c|}{ "LA CIUDAD DE ORO* } \\
\hline VERSION ORIGINAL & VERSION DOBLADA \\
\hline Tomás.- ¿Dónde quicres ir? & Tomás.- ¿Dónde quieres ir? \\
\hline Jobst.- $A$ la picdra donde percció su madrc. & Jobst.- $\Lambda$ la cru\% de la tumba de su madre. \\
\hline $\begin{array}{l}\text { Ana.- jUna luz, una lü! No me equivoco.. madre- } \\
\text { cita, ya voy. Padre, perdóname por causarte tanto } \\
\text { dolor, Ya sé que tú siempre me has querido. Padre, } \\
\text { perdóname porque yo no haya querido tanto como } \\
\text { tú a nuestro hogar... }\end{array}$ & $\begin{array}{l}\text { Ana.- Una lül iUna luz! ... Perdón, Dios mío. } \\
\text { Acoge mi alma! !Padrc, pcrdóname tú cl dolor que } \\
\text { tc causo. l'u siempre me has querido, padre. } \\
\text { l'crdona que haya abandonado nuestro hogat. }\end{array}$ \\
\hline Campesino.- ¡Vamos, cogedla! & Campesino.- Vamos. Cogedla. \\
\hline $\begin{array}{l}\text { Jobst.- Dejadme, a la casa pucdo llevarla yo mis- } \\
\text { mo. } A \text { la casa, a donde yo no la quería recibir. Pero, } \\
\text { Ana, aqui, aquí, ahora mismo, hemos de reparar al- } \\
\text { gunas cosas. }\end{array}$ & $\begin{array}{l}\text { Jobst.- Dejadla! Ja llevaré yo mismo. } A \text { mi casa, } \\
\text { donde no la quise recibir. !Mi pobre } A \text { a! No tuve } \\
\text { compasión de tí... Ya todo acabó para mi. }\end{array}$ \\
\hline $\begin{array}{l}\text { Pelikan.- Déjalo, Jobst, no te cntristécas ahora. } \\
\text { Eil tiempo lo arregla todo. Iul ticmpo cura. }\end{array}$ & $\begin{array}{l}\text { Pelikan.- Ven, Jobst. I-Iay que tener valor. El } \\
\text { ticmpo lo arregla todo. Sc fucrte. }\end{array}$ \\
\hline
\end{tabular}

Pero a falta de una investigación exhaustiva sobre la manipulación censota hemos de contentarnos con los escasos ejemplos que se han descrito hasta el momento, algunos verdaderamente ridículos como sucede en «Arco de Triunfon (1947) cuando preguntan a una mujer acompañada por su amante «Es su marido?" a lo que ella niega con la cabeza mientras sus labios pronuncian "sì) en castellano ${ }^{37}$.

Sin embargo, es importante aclarar que la manipulación mediante el doblaje también se debió a los hábitos de las distribuidoras para aumentar la comercialidad de sus productos, como sucedería en 1950 con la película «Ladrón de bicicletas» de Vittorio de Sica. Según la versión tradicional la comisión de censura añadió al final del metraje una voz en off con un mensaje reconfortante y esperanzador ${ }^{38}$; sin embargo, este inserto había sido en realidad idea del jefe de publicidad de la distribuidora que pretendía con ello reducir la crudeza del atgumento ${ }^{39}$.

\section{LA DEFENSA DEL IDIOMA ESPAÑOL}

Por otra parte, se comentó al princípio que buena parte de los historiadores atribuyen frecuentemente la imposición del doblaje a la defensa del idioma español. Vamos ahora a abordar esta cuestión.

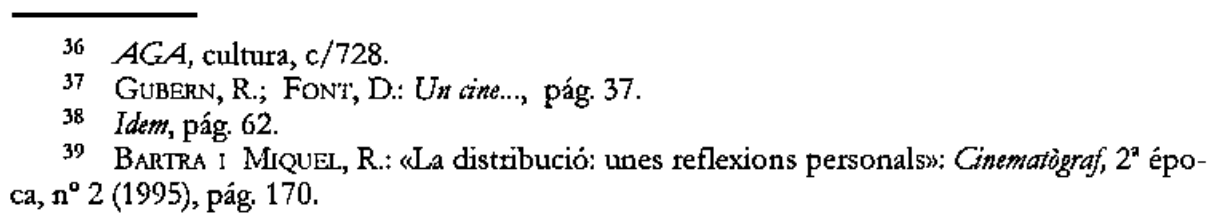

Hippania, LIX/2, núm 202 (1999) 677-691 
El contexto político y cultural durante la inmediata posguerra estuvo caracterizado por una evidente voluntad de imposición de la lengua castellana frente a la influencia de las lenguas extranjeras --prohibición de utilizar nombres extranjeros en marcas o nombres de empresas, establecimientos, compañías artísticas, etc. - tanto como frente a la influencia de las otras lenguas españolas - el catalán, el vasco y el gallego- prohibidas y perseguidas durante años.

Como reflejo de esta cuestión, en 1940 la revista «Primer Plano» reclama de la Real Academia Española una vigilancia permanente para evitar que términos extranjeros se instalen definitivamente en el argot cinematográfico. Pocos meses después se publica una encuesta entre ilustres académicos como Julio $\mathrm{Ca}$ sares, Joaquín Alvarez Quintero, Eduardo Marquina, Eugenio d'Ors y Federico García Sanchiz, con el objetivo de consensuar un argot genuinamente español, pero el resultado es francamente decepcionante: la palabra "play-back» debía ser substituida por "sonido superpuesto" (Casares), "bailable» o "cantable» (Marquina) o «acoplamiento» (Quintero); «script-girl» por «observadora», «secretaria» y «fijadora» respectivamente; y "maquillaje» por "caracterización» en los tres casos -ahí coincidían - aunque Joaquín Alvarez Quintero añadía que para las señoras era más apropiado el término shermoseo» ${ }^{40}$.

La restricción contra las otras lenguas españolas ya se había materializado en su momento cuando el Departamento Nacional de Cinematografia difundió una consigna que impedía el uso de los «dialectos»:

"Todas las películas deberán estar dialogadas en castellano, prescindiéndose, en absoluto, de los dialectos. En todo caso se admitirá una pronunciación dialectal en los personajes simplemente episódicos. ${ }^{41}$.

Sin embargo, y tal como observó en su día Román Gubern, el tabú contra la pronunciación dialectal fue aplicado de manera arbitraria y no afectó ni al "castizo», por ser una «sublimación populista (y demagógica) emanada de la Capital/Corte política del Estado centralistas, ni al andaluz "porque era el acento de la oligarquía agraria y latifundista fiel al franquismo» ${ }^{42}$. Tanto es así, que el andaluz se convirtió en acento principal de muchas películas, sobre todo de aquellas que pertenecían al género de la «españolada», llegando al extremo en alguna ocasión de escribirse con la grafía correspondiente, como en unos rótulos que aparecen en el film «La patria chica» (1943):

«Academia Ansúreq. Se enseña a bailá y a cantá mejó que ahi enfrente.

Baile y cante Medina. No lo crea, donde se enseña a cantá y a bailá es aquí.)

Pero en general, la vinculación de la obligatoriedad del doblaje con el nacionalismo linguístico no es del todo satisfactoria. En primer lugar, porque de ser

40 Primer Plano, 17 (9-2-1941).

41 Primer Plano, 1 (20-10-1941), pág. 3.

42 Gubern, R.: «La censura cinematogràfica ì la "Qüestió lingüistica sota el franquisme" $"$ : L'Avens, 59 (abril 1983), págs. 38-40. 
así, el texto legislativo que la impuso se habría acompañado de la retórica habitual en estas ocasiones, como cuando aparece en el preámbulo de la orden del 16 de mayo de 1940 prohibiendo el empleo de vocablos extranjeros en la denominación de empresas o establecimientos ${ }^{43}$ :

«No por un mezquino espiritu de xenofobia, sino por exigencias del respeto que debemos a to que es entrañablemente nuestro, como el idioma, precisa desarraigar vicios del lenguaje que, tras. cendiendo del ámbito parialmente incoercitible de la vida privada, permiten en la vida pública la presencia de modas con apariencia de vasallaje o subordinación colonial. Es deber del poder público, en la medida en que ello es posible, reprimir estos usos, que coniribuyen a enturbiar la conciencia española, desviándola de la pura linea nacional, introduciendo en las costumbres de nuestro pueblo elementos exóticos que importa eliminar."

En segundo lugar, porque las autotidades no habrían tenido ningún pudor en reconocer este hecho ante la opinión pública; más bien al contrario, presumirían de los beneficios derivados de la medida y de la inflexibilidad de su aplicación, unos valores de los que, por ejemplo, se mostraban orgullosos los vocales de las juntas de censura cinematográfica al justificat la necesidad de cortar las películas. Pero las declaraciones aparecidas en la prensa desde abril de 1941 se refieren exclusivamente a las virtudes económicas que se obtienen de la protección de la industria española y no a cuestión alguna ligada al idioma.

De esta forma, es evidente que la normativa sobre doblaje formaba parte de una disposición legislativa mucho más amplia -algo que normalmente se olvida - , que incluía otras medidas — todas de carácter comercial-, cuyo objetivo era la restricción de las importaciones. De ser otro el objetivo se habría promulgado, con toda probabilidad, una orden específica para resolver la cuestión del idioma .

Es cierto, sin embargo, que un oficio antes citado del Jefe del Sindicato $\mathrm{Na}$ cional del Espectáculo sobre los objetivos que debería tener la imposición del doblaje hacia referencia a la necesidad de evelat por la pureza del idioma», pero tampoco se especificaba exactamente el significado de la expresión, que tanto podía referirse a la necesidad de imponer la lengua castellana como a la de castigat el sistema del subtitulado por los frecuentes errores ortogtáficos que en él se apreciaban. Todo esto no excluye que el Sindicato Nacional del Espectáculo deseara realmente erradicar de la pantalla las otras lenguas, y en este sentido, Román Gubern ha observado oportunamente la conexión entre la imposición del doblaje y la fascista «Legge di Difesa dell'Idioma» en la que podría haberse inspirado ${ }^{44}$. Avala esta posibilidad el hecho de que el Jefe del Sindicato Nacional del Espectáculo, Tomás Borrás, reconociera en alguna ocasión que las medidas proteccionistas adoptadas tenían un paralelismo con la legislación italiana.

43 BOE, 17-5-1940.

44 GUBERN, R.: «Les rapports entre le cinéma mussolinien et le cinéma franquiste»: Risorgimento, $2-3$ (1981), pág. 200.

Hispania, LJX/2, núm. 202 (1999) 677-691 


\section{LA POLEMICA PUBLICA SOBRE EL DOBIAJE}

Pero en Italia la prohibición del doblaje sería derogada poco después de su implantación en España, debido, en parte, a una encuesta emprendida por la revista "Cinema». Este hecho seguramente alentó a su homóloga hispana la posibilidad de realizar una campaña similar. Por ello la revista "Primer Plano», en este momento directamente controlada por la Sección de Cinematografía y Teatro (antiguo Departamento Nacional de Cinematografia) que ya se había manifestado en diversas ocasiones contraria al doblaje, plantea una incómoda e implacable discrepancia respecto del parecer del Sindicato, el organismo que lo había impuesto. Alimenta esta polémica hacia 1943 y, desde luego, consigue que la mayor parte de los profesionales del sector se manifestaran en contra. Veamos, a continuación, un resumen de las posturas.

Los contrarios consideraban que la técrica del doblaje suplantaba la dicción del actor original por la de un doblador español, que ofrecía una interpretación considerada como de inferior calidad y para la cual no habían pagado, y que además se suprimía la banda sonora original del film —músicas, sonidos, etc.-, con todo lo que ello comportaba de empobrecimiento de sus valores artísticos. Pero el doblaje tenía, además, un terrible aspecto económico ya que facilitaba la competencia del cine extranjero porque los espectadores podrían ver sus películas en igualdad de condiciones que las españolas al suprimirse el inconveniente de los subtítulos. Pretendían que las películas nacionales gozaran de un trato de favor ya que sus posibilidades de amortizar los costos de realización eran menores al exhibirse en un mercado con un potencial de público bastante más reducido.

Las manifestaciones de los detractores llegaron a ser bastante exaltadas adoptando un lenguaje muy severo contra el doblaje al que calificaban como antiestético, absurdo, monstruoso, etc., bien que sin el menor reproche hacia el organismo que había instaurado esa medida, aunque en el caso de existir seguramente habría sido eliminado por la censura. Sirva de muestra del ambiente el testimonio del director José López Rubio:

«De seguir como basta boy, con la gravedad que aumenta dramáticamente a cada bora que pasa, ante la perspectiva de la peor temporada para la indefensa industria nacional, vale más cerrar nuestros Estudios o convertirlos de una vez en laboratorios de injertos vocales; reducir a nuestros actores a anónimos donadores de voces, nuestros escritores a traductores de silabas; $b$ cenciar una legión de directores, técnicos y obreras y matar la ilusión de los que ban de llegar al cine con la fuerza nueva de su juventud.» 45 .

A grandes rasgos estos fueron los argumentos esgrimidos por los críticos del doblaje a lo largo de innumerables artículos firmados por prestigiosos directores como José Luis Sáenz de Heredia, Antonio Román, Edgar Neville, Florián Rey o José Buchs - por citar tan sólo algunos-; y también por críticos de cine, como Alfonso Sánchez, Luís Gómez Mesa o Angel Zúniiga.

\footnotetext{
45 Declataciones del director López Rubio a Primer Plano, 165 (12-12-1943), pág. 3.
} 
Sin embargo, sería injusto olvidar algunas voces favorables, o al menos, algo más flexibles que también aparecieron en la revista. El director Carlos Arévalo, por ejemplo, considera que el doblaje es un incentivo de la asistencia de los espectadores al cine, en general ${ }^{46}$; y el productor Serafín Ballesteros opina que el cine español tiene un techo en cuanto a recaudaciones y número de espectadores que no puede aumentar por mucho que se suprima el doblaje:

«Ahora parece que de suprimir el doblaje depende todo. El que las malas peliculas españolas se conviertan en buenas, el que se gane en las que se pierde. El que surja por maravilla una clientela de espectadores que se pegue en las colas que se formarán ante las taquillas de «todas» las peliculas españolas. El aumento de nuestra producción, la conquista del prestigio y los mercados en el Extranjero. Todo, todo parece que se conseguirá fulminantemente con tan simple metodo., 47 .

La postura combativa de la revista «Primer Plano» se explicaría, según José Enrique Monterde, por su vinculación a círculos falangistas y sindicales implicados en el sector de la producción que era el más perjudicado con la imposición del doblaje ${ }^{48}$. Desgraciadamente, sin embargo, no se aportan datos que avalen tal afirmación.

La polémica se extendió, además, a otros međios de comunicación. Fue un hecho insólito - por lo infrecuente- que no tenía apenas paralelo en la prensa española tan controlada y manipulada en tantos aspectos por los poderes públicos. De esta forma, la polémica permitiría reflexionar sobre el impacto de las diversas medidas económicas y gracias a ello fueron filtrándose en la prensa juicios cada vez más críticos con la política oficial. El doblaje y las otras medidas de protección a la industria serían consideradas como perjudiciales en diversos artículos que se distinguieron por mostrar frustración y amargura por la ausencia de lo que debería haber sido el gran cine español. Un editorial de la revista «Primer Plano» firmado con el seudónimo "XXX» y titulado "Crisis de una política cinematográfica» constataba este hecho con la mayor rotundidad:

"No cabe duda, por desgracia, que la politica cinematográfica española, es deitr, las normas aplicadas durante cuatro años para alcanzar el objetivo de «crear un cine nacionals, han fracasado de manera visible. [...]

A los pocos meses de establecerse las llamadas normas protectoras del cine nacional, ya no podía ser más sombrio el porvenir de éste, $[. . \cdot]$ se perfeccionaban «obligatoriamente» las peliculas extranjeras mediante el doblaje, cuando lo comercial basta entontes babia sido la contratación delproducto extranjero gracias a las peliculas españolas; se entregaba el propio mercado, nuestro mercado, al cine extranjero, apartando a nuestro público del ambiente cinematográfico nacional e incluso del clima moral y social de nuesira Patria.» ${ }^{4}$.

46 Primer Plano, 131 (18-4-1943), pág. 15.

47 BA.J.ESTEROS, S.: «Para navegar en un mar de confusiones. Del estado actual del cine español, del doblaje y de otras cosas más): Primer Plano, 172 (30-1-1944), pág. 3.

48 MONTERDE: «EI cine...», pág. 193.

4) «XX « «Crisis de una política cinematográfica»: Primer Plano, 242 (3-6-1945), pág. 3. 
En este contexto, la Sección de Cinematografía y Teatro no dejó de presionar para imponer su punto de vista y preparó en septiembre de 1943 una orden que no llegó a aplicarse para derogar progresivamente la obligatoriedad del doblaje aludiendo a «la situación de privilegio que viene creándose en torno a las producciones cinematográficas extranjeras, con grave quebranto para el propósito estatal de crear un cine españob» y al peligro de que "al dotar a todas las películas extranjeras de nuestro idioma, surja como consecuencia inevitable la admisión y tolerancia e incluso la adopción de normas de vida y principios sociales ajenos en absoluto a nuestra cultura y formación espirituaby ${ }^{50}$. Curiosamente, los argumentos de este organismo se apoyaban en la idea de que el doblaje de las películas extranjeras facilita la contaminación de las costumbres nacionales, insinuando, por tanto, que lo patriótico era el sistema del subtitulado.

Con todo, y por razones que desconocemos todavía con exactitud, a finales de 1946 se consiguió derogar la obligatoriedad del doblaje y las películas podrían a partir de ahora exhibirse en su idioma original aunque ello no comportara, como medida discriminatoria positiva, la imposición del sistema del subtitulado ${ }^{51}$ :

"1 ${ }^{\circ}$ A partir del dia 1 de enero de 1947, las autorizaciones de doblaje al castellano de las peliculas extranjeras destinadas a su exhibición en España se concederán única y exclusivamente a aquellas personas o entidades que produzcan peliculas nacionales que, for su calidad técnicoartistica, obtengan la aprobación de la Junta Superior de Orientación Cinematográfica.

$[..] 7^{\circ}$ Las peliculas extranjeras que no posean permisos de doblaje serán explotadas en su versión original, pudiendo ser rotuladas en castellano [...]."

Pero en realidad, esta disposición no pretendía erradicar el doblaje sino meramente utilizatlo como un premio a los productores de buenas películas que, de esta forma, podían vender las licencias de doblaje a las distribuidoras. Y como recordaba hace años José María García Escudero, Director General de Cinematografia durante los años 50 , las empresas de la producción podian haberse guardado previsoramente los permisos para conseguir la disminución de la competencia de las películas extranjeras pero prefirieron el beneficio inmediato de su venta ${ }^{52}$. De esta forma, el doblaje se mantendría inamovible y las películas en versión original con subtítulos no se exhibirian salvo en las contadas sesiones especiales organizadas por los cine-clubs.

50 "Propuesta de otden", [15-9-1943]. AGA, sección cultura, $\mathrm{C} / 647$.

51 Orden del 31-12-46 sobre doblaje al castellano de películas extranjeras. BOE, 25-11947.

52 García Escudero, J. M.: Cine español. Madrid 1962, pág. 93.

Hispunia, LIX/2, nüm 202 (1999) 677-691 